\title{
Effect of Mobile Phone Short Text Messages on Glycemic Control in Type 2 Diabetes
}

\author{
Bassam Bin Abbas ${ }^{1, *} ;$ Abdullah Al Fares ${ }^{1} ;$ Musleh Jabbari ${ }^{2} ;$ Abdelmoneim El Dali $^{3}$; Fahad Al \\ Orifi $^{4}$ \\ ${ }^{1}$ Department of Pediatrics, Security Forces Hospital, Riyadh, Saudi Arabia \\ ${ }^{2}$ Imam University, Riyadh, Saudi Arabia \\ ${ }^{3}$ Department of Biostatistics, Epidemiology and Scientific Computing, King Faisal Specialist Hospital and Research Center, Riyadh, Saudi Arabia \\ 4 Department of Telemedicine and E-Health, King Faisal Specialist Hospital and Research Center, Riyadh, Saudi Arabia \\ *Corresponding author: Bassam Bin Abbas, Department of Pediatrics, Security Forces Hospital, P. O. Box:3354, Riyadh, Saudi Arabia. Tel: +966-534341777, Fax: +966-114427784, E-mail: \\ b.binabbas@gmail.com
}

Received: March 6, 2014; Revised: August 13, 2014; Accepted: September 1, 2014

\begin{abstract}
Background: Mobile phone text messaging has rapidly become a socially popular form of communication. Several studies showed that mobile phone might offer a useful means of providing information between clinic visits and might increase adherence to diabetes therapy regimens.

Objectives:We conducted a study to evaluate the effect of mobile phone short message service(SMS)on glycemic control in Saudi patients with type 2 diabetes.

Patients and Methods: One hundred patients (mean age, $41 \pm 9.5$ years) were selected at the Security Forces Hospital, Riyadh, Saudi Arabia, and provided with daily educational, reminding SMS messages for four months. Glycosylated hemoglobin (HbA1c) level, frequency of hypoglycemic and hyperglycemic attacks, and compliance with blood glucose monitoring were recorded before and after the trial.

Results: In addition to significant improvement in patients' knowledge, mean fasting blood glucose level improved from $8.60 \pm 3.16$ to 7.77 $\pm 3.11 \mathrm{mmol} / \mathrm{L}$ and mean HbAic decreased from $9.9 \% \pm 1.8 \%$ to $9.5 \% \pm 1.7 \%$.

Conclusions: Mobile phone text messaging increased adherence to diabetes therapy and improved the clinical outcome in Saudi patients with type 2 diabetes.
\end{abstract}

Keywords:Diabetes Mellitus, Type 2; Cellular Phone; Health; Glycemic; Text Messages

\section{Background}

Mobile phone text messaging has rapidly become a socially popular form of communication. It is personal, highly transportable, and widely used, particularly in the Western countries $(1,2)$. However, text messaging coupled with specific management strategies has yet to be utilized effectively in developing countries with high prevalence of diabetes. Several studies showed that mobile phone might offer a useful means of providing information between clinic visits and might increase adherence to diabetes therapy regimens (3-5).

\section{Objectives}

The aim of this study was to evaluate the feasibility of short message service (SMS) and its effect on glycemic control in adults with type 2 diabetes.

\section{Patients and Methods}

It was a prospective nonrandomized experimental trial for a four-month period. A total of 100 patients with type 2 diabetes with disorder duration of more than one year and no end organ complications who were on oral hypoglycemic agents and were followed at the Diabetes Clinics, Security Forces Hospital, were recruited. The following parameters were recorded before initiating sending SMS: glycosylated hemoglobin (HbA1c), frequency of simple hypoglycemic attacks (defined as blood glucose level $<2.22 \mathrm{mmol} / \mathrm{L}$ ), frequency of severe hypoglycemic attacks (hypoglycemia associated with seizure or come), frequency of hyperglycemic attacks (defined as blood glucose of $>9.99 \mathrm{mmol} / \mathrm{L}$ ), mean fasting blood sugar (FBS) level, mean postprandial blood glucose level, and frequency of blood glucose monitoring. Twenty educational multiple-choice questions for assessing patients' knowledge were distributed. After four month of sending SMS, the above parameters were recorded again and ten scoring questions to assess the quality of SMS were answered by the participants.

The content of the SMS program short messages prepared in simple, understandable, constructive Arabic language. Five to seven messages were sent each week. The educational messages covered general diabetes care

Copyright (C) 2015, Research Institute For Endocrine Sciences and Iran Endocrine Society. This is an open-access article distributed under the terms of the Creative Commons Attribution-NonCommercial 4.0 International License (http://creativecommons.org/licenses/by-nc/4.0/) which permits copy and redistribute the material just in noncommercial usages, provided the original work is properly cited. 
Bin Abbas B et al.

knowledge that included diabetes symptoms, signs, pathophysiology, etiology, diagnosis, diet therapy, psychotherapy, press news concerning diabetes, etc. These messages were considered as reminding messages about blood glucose check-up and medications intake. The main educational goal was to improve knowledge and subsequently attitude and practice. The messages were written by specialist in diabetes and diabetic educators, and then reviewed by the authors. Phone calls were made to ensure that SMS had been received. All SMS submitted to the participants during the four-month period were recorded.

Statistical analyses were performed using the Wilcoxon signed rank test, to evaluate the differences in HbA1c, FBS, postprandial blood glucose levels, incidence of hypoglycemic/hyperglycemic episodes, and other variables before and after the intervention. The tests were two tailed and $\mathrm{P}<0.05$ was considered as significant deviation from the null hypothesis. The study was approved by the Research Ethics Committee. A written informed consent with the Security Forces Hospital Institutional Board Review approval was obtained from participants.

\section{Results}

The average number of submitted SMS messages was six messages (range, 5-7) per patient per week with the total number of approximately 9600 messages over four months for all patients. A total of 100 phone calls were primarily made to ensure that the patients had received the messages at the middle the trial. One month prior to SMS delivery, the mean FBS level was $8.60 \pm 3.16 \mathrm{mmol} / \mathrm{L}$, the mean postprandial blood glucose level was $10.98 \pm$ $4.03 \mathrm{mmol} / \mathrm{L}$, the median frequency of documented simple hypoglycemic and hyperglycemic attacks per week were respectively zero and two, the mean HbAic was 9.9\% $\pm 1.8 \%$, the median frequency of blood glucose monitoring per day was zero, and the median score at the patient's knowledge testing was 17 (the maximum score was 20).

Post-SMS delivery and during the last month of the teleeducational period were as follow: the mean FBS level, $8.60 \pm 3.16 \mathrm{mmol} / \mathrm{L}$; the mean postprandial blood glucose level, $10.65 \pm 3.20 \mathrm{mmol} / \mathrm{L}$; the median frequency of documented simple hypoglycemic and hyperglycemic attacks per week, zero and two, respectively; the mean HbA1c, $9.5 \% \pm 1.7 \%$, the median frequency of blood glucose monitoring per day, one; and the median score at the patients' knowledge testing, 19. There was no report of severe hypoglycemic attacks (Table 1). The mean score of SMS quality, assessed by the parents, was 8.7 out 10 .

\section{Discussion}

Growing evidence suggests that utilizing mobile phones might improve diabetes self-management and clinical outcomes (6-10). A meta-analysis examined the effectiveness of mobile phone technology in diabetes mellitus care by reviewing 15 English-language articles, published between January 2002 and March 2012. Studies that used mobile phone intervention and reported changes in diet, physical activity, and blood glucose and/or HbAic levels were retrieved. Overall, significant improvements were observed in blood glucose and/or HbA1c concentration, adherence to medication, healthy lifestyle, and self-efficacy (11). These studies took place in several countries including the United States. Our Study is probably among the first ones to be conducted in the Arab peninsula where diabetes prevalence is very high. In our study, the change in post prandial blood sugar was remarkable, which significantly decreased the level of HbAic.

Holtz et al. identified peer-reviewed articles published between 2000 and 2010 and analyzed 21 articles in a systematic literature review. Overall, $71 \%$ of the studies had used a study-specific application, which had supplemental features in addition to text messaging. The outcomes varied considerably across studies, but some positive trends such as improved self-efficacy, $\mathrm{HbA1C}$, and selfmanagement behaviors were noted (12). In our cohort, SMS positively modified patients' behavior. Although the frequency of blood glucose monitoring was not increased significantly, the rate of glycemic control was improved.

A feasibility study was conducted to evaluate the utility of SMS in supporting 42 Iraqi adults with newly diagnosed type 2 diabetes over 29 weeks. HbAlc decreased from $9.3 \%$ (SD, 1.3\%) to $8.6 \%(\mathrm{SD}, 1.2)(\mathrm{P}=0.001)$. Mean knowledge score rose from 8.6 (SD, 1.5) at baseline to 9.9 $(\mathrm{SD}, 1.4)$ six months after receipt of SMS $(\mathrm{P}=0.002)$. All patients were satisfied with the text messages and wished the service to be continued after the study (13). Our study demonstrated similar benefits of this technology on diabetes education and management.

Table 1. Effects of Short Message Service on Glycemic Control, Knowledge, and Monitoring Compliance of Patients With Type 2 Diabetes $a, b$

\begin{tabular}{|c|c|c|c|}
\hline Variable & $\begin{array}{l}\text { Pre-SMS } \\
\text { Initiation }\end{array}$ & $\begin{array}{c}\text { Post-SMS } \\
\text { Initiation }\end{array}$ & PValue \\
\hline FBS, mmol/L & $8.60 \pm 3.16$ & $7.76 \pm 3$ & 0.001 \\
\hline $\begin{array}{l}\text { Postprandial blood glu- } \\
\text { cose, mmol/L }\end{array}$ & $\begin{array}{c}10.98 \pm \\
4.03\end{array}$ & $10.65 \pm 3.20$ & 0.195 \\
\hline $\begin{array}{l}\text { Frequency of simple hypo- } \\
\text { glycemic attacks per week }\end{array}$ & $0(1)$ & $0(0)$ & 0.436 \\
\hline $\begin{array}{l}\text { Frequency of hyperglyce- } \\
\text { mic attacks per week }\end{array}$ & $2(2)$ & $2(2)$ & 0.052 \\
\hline HbA1c, \% & $9.9 \pm 1.8$ & $9.5 \pm 1.7$ & 0.014 \\
\hline $\begin{array}{l}\text { Frequency of blood glu- } \\
\text { cose monitoring per day }\end{array}$ & $0(1)$ & $1(1)$ & 0.428 \\
\hline $\begin{array}{l}\text { Score of the patients' } \\
\text { knowledge test }\end{array}$ & $17(6)$ & $19(5)$ & $<0.0001$ \\
\hline
\end{tabular}

${ }^{a}$ Data are presented as median (interquartile range) or mean \pm SD.

b Abbreviations: SMS, short message service; FBS, fasting blood sugar; and HbA1c, glycosylated hemoglobin. 
The effect of distance education via mobile phone text messaging on knowledge, attitude, practice, and selfefficacy was evaluated in patients with type 2 diabetes mellitus in Iran. The results in the experimental group showed significant improvement in HbA1c $(P=0.024)$, low density lipoprotein $(\mathrm{P}=0.019)$, cholesterol $(\mathrm{P}=$ $0.002)$, and micro albumin ( $\mathrm{P} \leq 0.001)$. The knowledge $(\mathrm{P} \leq 0.001)$, practice $(\mathrm{P} \leq 0.001)$, and self-efficacy $(\mathrm{P} \leq$ 0.001) were also improved (14).

In a randomized study in India, the acceptability and feasibility of using SMS via cell phones to ensure adherence to management prescriptions was tested. Medications adherence improved and positively affected HbA1c and plasma lipids levels (15). We did not test medications adherence in our study; however, the patients admitted that their compliance with drug intake was better. A oneway video message about diabetes self-care was sent to 65 patients with type 2 diabetes for one year. Participants were randomized to receive the usual care or the self-care video messages from their diabetes nurse practitioner. Participants who received the messages had a larger rate of decline in HbA1c than people who received usual care had ( $0.2 \%$ difference over 12 months) (16). We believe that multimedia message service might have a better audiovisual effect in comparison to regular SMS; however, it should be tested in further studies.

Mobile phone text educational and interactive messaging service might provide benefit in supporting diabetes self-management. The results of this study might help to design future text message interventional support programs for other chronic illnesses.

\section{Acknowledgements}

The authors express their thanks to Dr. Hamad Al-Omar, Mobile Health Company, and all employees for their help in dealing with all technical issues related to SMS/MMS preparation, processing, and sending.

\section{References}

1. Dick JJ, Nundy S, Solomon MC, Bishop KN, Chin MH, Peek ME. Feasibility and usability of a text message-based program for diabe- tes self-management in an urban African-American population. $J$ Diabetes Sci Technol. 2011;5(5):1246-54.

2. Cole-Lewis H, Kershaw T. Text messaging as a tool for behavior change in disease prevention and management. Epidemiol Rev. 2010;32(1):56-69.

3. Liang X, Wang Q, Yang X, Cao J, Chen J, Mo X, et al. Effect of mobile phone intervention for diabetes on glycaemic control: a metaanalysis. Diabet Med. 2011;28(4):455-63.

4. Kim HS, Jeong HS. A nurse short message service by cellular phone in type-2 diabetic patients for six months. J Clin Nurs. 2007;16(6):1082-7.

5. Kim CS, Park SY, Kang JG, Lee SJ, Ihm SH, Choi MG, et al. Insulin dose titration system in diabetes patients using a short messaging service automatically produced by a knowledge matrix. Diabetes Technol Ther. 2010;12(8):663-9.

6. Hanauer DA, Wentzell K, Laffel N, Laffel LM. Computerized Automated Reminder Diabetes System (CARDS): e-mail and SMS cell phone text messaging reminders to support diabetes management. Diabetes Technol Ther. 2009;11(2):99-106.

7. Wangberg SC, Arsand E, Andersson N. Diabetes education via mobile text messaging. J Telemed Telecare. 2006;12 Suppl 1:55-6.

8. Arsand E, Froisland DH, Skrovseth SO, Chomutare T, Tatara N, Hartvigsen G, et al. Mobile health applications to assist patients with diabetes: lessons learned and design implications. J Diabetes Sci Technol. 2012;6(5):1197-206.

9. Arora S, Peters AL, Agy C, Menchine M. A mobile health intervention for inner city patients with poorly controlled diabetes: proof-of-concept of the TExT-MED program. Diabetes Technol Ther. 2012;14(6):492-6.

10. Zolfaghari M, Mousavifar SA, Haghani H. Mobile phone text messaging and Telephone follow-up in type 2 diabetic patients for 3 months: a comparative study. J Diabetes Metab Disord. 2012;11(1):7.

11. Liu L, Ogwu SM. A Meta-Analysis of Mobile Health and Risk Reduction in Patients with Diabetes Mellitus: Challenge and Opportunity. J Mobile Technol Med. 2012;1(3):17-24.

12. Holtz B, Lauckner C. Diabetes management via mobile phones: a systematic review. Telemed J E Health. 2012;18(3):175-84.

13. Haddad NS, Istepanian R, Philip N, Khazaal FA, Hamdan TA, Pickles $\mathrm{T}$, et al. A feasibility study of mobile phone text messaging to support education and management of type 2 diabetes in Iraq. Diabetes Technol Ther. 2014;16(7):454-9.

14. Goodarzi M, Ebrahimzadeh I, Rabi A, Saedipoor B, Jafarabadi MA. Impact of distance education via mobile phone text messaging on knowledge, attitude, practice and self efficacy of patients with type 2 diabetes mellitus in Iran. J Diabetes Metab Disord. 2012;11(1):10.

15. Shetty AS, Chamukuttan S, Nanditha A, Raj RK, Ramachandran A. Reinforcement of adherence to prescription recommendations in Asian Indian diabetes patients using short message service (SMS)--a pilot study. J Assoc Physicians India. 2011;59:711-4.

16. Bell AM, Fonda SJ, Walker MS, Schmidt V, Vigersky RA. Mobile phone-based video messages for diabetes self-care support. J Diabetes Sci Technol.2012;6(2):310-9. 